\title{
Decomposing the productivity index in its main factors, applied at the MSME of graphic arts. Case study.
}

\author{
Juan Victor Bernal - Olvera, M. A. ${ }^{1}$, Eduardo Oliva - López, Ph. D. ${ }^{2}$ \\ ${ }^{1}$ Tecnológico de Estudios Superiores de Cuautitlán Izcalli, and Instituto Politécnico Nacional, Mexico,jvbernal@tesci.edu.mx, \\ ${ }^{2}$ Instituto Politécnico Nacional, Mexico, eoliva@ipn.mx
}

\begin{abstract}
It is limited the information provided by the productivity index, which only measures the relationship between production and the resources used to obtain it; in addition, this index is a relative measure and in the past tense. How can a MSME improve productivity with this number? This work shows the decomposition of the productivity index in its mains factors, Labor and Capital, through applying Cobb - Douglas Production Function, into a study case over a graphic arts Mexican manufacturer of equipment. The results show that it is possible to use the proposed productivity index in this work, doing the validation with de typical Sumanth mathematical expression, finding no significant difference between both equations.

Keywords-Productivity, MSME, Labor, Capital, measurement.
\end{abstract}

\section{INTRODUCTION}

There are many way to get the productivity index, but all of them coincide in relating the production outputs with the resources used to achieve them. Nevertheless, the question is what is the utility of this result for MSME? How are the resources of the MSME being used at this time, according to this result?

The importance of this point is around of global competitiveness, as a consequence, the manufacturing industry is constantly under tough pressure to increase its competitiveness [1]. To be able to maintain and develop their ability to compete on a global market, manufacturing companies need to be successful in developing innovative and high - quality products with short lead times, as well as in designing robust and flexible systems providing the best preconditions for operational excellence [2].

Productivity accounts for half of the differences in GDP per capita across countries. Identifying policies to stimulate it is thus critical to alleviating poverty and fulfilling the rising aspirations of global citizens. Yet productivity growth has slowed globally in recent decades, and the lagging productivity performance in developing countries constitutes a major barrier to convergence with advanced-economy levels of income [3].

Because it is a core part in the growth of the countries, their increase of competitiveness level, and affect to the inflation rate and improve life quality, one of relevant concept in the economic processes is the productivity [4]. Increasing it

Digital Object Identifier (DOI):

http://dx.doi.org/10.18687/LACCEI2020.1.1.302

ISBN: 978-958-52071-4-1 ISSN: 2414-6390 in a company or organization is essential to decrease the cost of production, to produce more efficiently and, therefore, to be able to compete with others in today's highly challenging market conditions [5]. But, in the first step, it is necessary to understand the productivity index, identifying its main factors to develop the best way to improve its final result.

\section{A. Evolution of Productivity concept}

Productivity is a concept that has been present in the analysis of many people from different professions, including engineers and economists and it has developed historically. Thus, for Sumanth [6], the first time that reference was made to this concept was in 1766 in the work of François Quesnay, French economist, who affirmed that the rule of fundamental conduct is to achieve the greatest satisfaction with the least expense or fatigue, whose approach is directly related to utilitarianism and in it are present the antecedents that point to productivity and competitiveness.

From the economic perspective, Adam Smith in his work, The Wealth of Nations, alludes to the term, when he points out that the annual product of the land and labor of the nation, can only be increased by two procedures: or with an advance in the productive faculties of the nation useful work that is maintained within them, or by some increase in the amount of that work. In 1883, Littre defined productivity as the power to produce. In 1898, Wright studied the behavior of productivity in the manufacturing sector and in 1900, Early defined productivity as the relationship between production and the means used to achieve it [4].

David Ricardo, an English economist, who raised the theory of value, absolute advantages and comparative advantages, relates productivity to the competitiveness of countries in the international market, incorporating the idea of decreasing returns in the use of factors [7]. Marx [8] defines labor productivity as an increase in production from the development of the productive capacity of labor without changing the use of labor power, while the intensity of labor is an increase in production at starting from increasing the effective time of work, reducing downtime and/or increasing the workday. An important element in the concept of productivity of Marx is that it incorporates in its definition, in addition to the skills of workers, the characteristics of science and technology incorporated in the production process [4]. 
In 1924 the Hawthorne Studios began an attempt to improve worker productivity at the Hawthorne Works of the Western Electric Company in Cicero, Illinois. However, ultimately, many managers and academics considered this exhaustive study, whose results were published in 1939 during the Great Depression, under the title Management and the Worker, as a manifesto that offered a new vision to rebuild a shattered world of meanings for the management grant and organizational life [9]. It became evident from these studies that the informal associations found in organizations profoundly affect the motivation, the level of production and the quality of individual work [10].

The Total Productivity of Factors (TFP), defined as the relationship between the real product and the actual use of factors or inputs, it was introduced into the economic literature by J. Tinbergen at the beginning of the forty's decade. Independently, this concept was developed by $\mathrm{J}$. Stigler, and later used and reformulated in the fifties and sixties by various authors, including J. W. Kendrick, R. Solow, and E. F. Denison. More recently, the contributions of H. Lydall, W. E. Diewert, L. R. Christensen and D. Jorgenson stand out in this line of research [11].

Until 1950, the European Organization for Economic Cooperation, provides a much more formal definition: the quotient obtained by dividing the output by one of the factors of production. As of this decade, the managers of some companies in North America emphasized the production function. In the following decade, the study of markets was positioned as the main strategy. Between the '70s and the beginning of the '80s, corporate acquisitions and mergers depended to a large extent on the power of finance. In 1979 Sumanth [6] proposes a model of total productivity that relates quality, technology and productivity. In the second half of the 80s and the beginning of the $90 \mathrm{~s}$, management began to highlight the importance of quality at the managerial level.

In 1984 Goldratt [12] published his advances in the theory of restrictions, which bases his work on labor efficiency through the detection and elimination of bottlenecks, improving the production and efficient use of resources, in a methodology that has a sequence of recursive application and business application.

\section{B. The Mexican MSME of graphic arts}

$\mathrm{SAB}$ is an MSME in Mexico's Valley, at the northwest limit with Mexico City. It is a manufacturer of different kinds of machinery and equipment for the silk screen printing process. It was founded in 1976, and now it lives its second management generation. It has as a leader product in sales, a printer machine, although its operation covers the sale of supplies related to this printing way. It has a familiar structure, with a traditional technology in its process of manufacture production.

\section{FRAME OF REFERENCE}

\section{A. Productivity in the literature}

Even though productivity is an extremely common measure, there is no commonly used definition on an operationalized level [1]. The high industrial application rate has therefore resulted in many definitions of productivity concept, all of them basically emanating from the general definition given by Sumanth [6]: Productivity is the quotient between outputs and entries.

This definitely must be operationalized in order to be useful. A variety of partial and total productivity measures are used in the industry. The use of partial measure has the drawback is that the impact from only one parameter is viewed, which might lead to a false indication about overall productivity [1].

Kaplan and Cooper [13] define productivity as the ratio of what is produced to what is required to produce it. Productivity measures the relationship between output such as goods and services produced, and inputs, which include labor, capital, material and other resources.

For Bernolak [14], productivity is a comparison of the physical inputs to a factory with the physical output from a factory. It means, Grünberg says, how much and how well produced from the resources used. By resources it means all the physical and human resources, including the people who produce the goods or provide the services, and the assets with which the people can produce or provide the services. He notes that performance measures sometimes turn out to resemble productivity measures, sometimes making it difficult to identify whether a measure is a performance measure or a productivity measure [15]. This is in contradiction to White [16], who includes several productivity measures in his array of performance measures.

Huang et al. [17] claim that productivity measures including Overall Throughput Effectiveness (OTE) and Cycle Time Effectiveness (CTE) can be derived based on Overall Equipment Efficiency (OEE). Chakravarthy et al. [18] present the measure Overall Equipment Productivity (OEP), also based on OEE together with an $\mathrm{X}$ - factor that determines the cycle time share of the total process time. In fact, OEE could be considered a subset of productivity since OEE improvements also improve the productivity level.

\section{B. Some Productivity indexes}

There are some productivity indexes applies in the enterprises; among the most prominent are the following.

Total Factor Productivity (TFP) is an index number representing technology shifts from output growth that is unexplained by input growth [19]. Over the last decades, consciousness has developed that ignoring inefficiency may bias TFP measures. Nishimizu and Page [20] decomposing TFP into a technical change component and a technical efficiency change component.

Digital Object Identifier: (only for full papers, inserted by LACCEI)

ISSN, ISBN: (to be inserted by LACCEI).

$18^{\text {th }}$ LACCEI International Multi-Conference for Engineering, Education, and Technology: "Engineering, Integration, and Alliances for a Sustainable Development" "Hemispheric Cooperation for Competitiveness and Prosperity on a Knowledge-Based Economy", 29-31 July 2020, Buenos Aires, Argentina. 
Caves, Christensen and Diewert [21] analyze discrete time Malmquist input, output and productivity indices using distance functions as general representations of technology. This index is related to the Törnqvist productivity index that uses both price and quantity information but needs no knowledge on the technology [22]. Färe, Grosskopf, Norris, and Zhang propose a procedure to estimate the Shephardian distance functions in the Malmquist productivity index by exploiting their inverse relation with the radial efficiency measures computed relative to multiple inputs and outputs nonparametric technologies [23]. They also integrate the two parts Nishimizu and Page decomposition. The underlying distance functions of this Malmquist productivity index have also been parametrically estimated [24].

Bjurek proposes a Hicks-Moorsteen TFP index that can be defined as the ratio of a Malmquist output- over a Malmquist input-index [25]. These Malmquist and HicksMoorsteen productivity indexes are known to be identical under two strong conditions: (i) inverse homotheticity of technology; and (ii) constant returns to scale [26]. Therefore, both indices are in general expected to differ, since the conditions needed for their equality are unlikely to be met in empirical work.

Chambers, Färe and Grosskopf [27] introduce the Luenberger productivity. These directional distance functions generalize the Shephardian distance functions by allowing simultaneous input reductions and output augmentations and they are dual to the profit function indicator as a differencebased index of directional distance functions [28]. Briec, Kerstens and Vanden Eeckaut define a LuenbergerHicksMoorsteen TFP indicator using the same directional distance functions [29]. Luenberger output, or input, oriented productivity indicators and Luenberger-Hicks-Moorsteen productivity indicators coincide under two demanding properties: (i) inverse translation homotheticity of technology; and (ii) graph translation homotheticity. Though not as popular as the Malmquist productivity index, the Luenberger productivity indicator has recently been used rather widely as a tool for empirical analysis [22].

\section{Cobb-Douglas Production Function}

It is possible to know the level of competitiveness and productivity of a MSME, in terms of investment of labor and capital, adapting a model through of the production function of Cobb - Douglas [30]; it is a form that has been studied and applied to model the productive process of the company [31 to 34]. Its basic formulation is presented in Equation 1.

$$
p=f(x, y)=A x^{\propto} y^{(1-\propto)}
$$

Where $\boldsymbol{x}$ is the Labor quantity, in hours per year; $\boldsymbol{y}$ is the Capital; $\boldsymbol{A}$ is a productivity constant; $\boldsymbol{\alpha}$ is the elasticity factor, and $\boldsymbol{p}$ is the production volume. Equation 1 has the following properties:

1. To say $p$ represents the actual production volume is to give particular expression to a well - known theory.

2. $p$ approaches zero as either Labor or Capital approaches zero.

3. $p$ approximates actual production over the period.

4. The first derivative of $p$ with respect to Labor is $\propto \mathrm{p} / \mathrm{x}$.

5. The first derivative of $p$ with respect to Capital is $(1-\propto) \mathrm{p} / \mathrm{y}$.

6. The elasticity of the product with respect to small changes in Labor alone is $\alpha$.

7. The elasticity of the product with respect to small changes in Capital alone is $1-\propto$.

Depending on the values of $\propto$, small changes will be more significant in the volume of production $\mathrm{p}$ attributable to Labor or Capital, that is, if the value of $\propto$ is greater for the Labor, then small changes will have more impact on the value of $\mathrm{p}$.

This theory of production relates the values of Capital and labor through a level of efficiency in the use of resources, individually and collectively, making interpretation easier, as well as the possibility of generating strategies for improvement in these two vectors

D. Productivity index using Cobb - Douglas production function

Productivity is a quotient that relates the volume of production with the inputs to achieve it; so, in this case, the Cobb - Douglas production function can define this production volume, then it is divided between the inputs to achieve it. In this manner, the productivity index can be expressed in terms of Capital and Labor. Then, the index $\boldsymbol{i}_{\boldsymbol{p}}$ that involves this math expression is shown in Equation 2.

$$
i_{p}=\frac{A x^{\propto} y^{(1-\propto)}}{c x+y}
$$

Where $c$ is the cost per hour in the Labor, in Mexican money.

\section{E. Mexican MSME and the graphic arts}

According to Statistical Information of Population from Mexico, INEGI [35], the Graphic Arts Industry represents a total national GDP of $1.033 \%$, with approximately 24,654 registered economic units, which have employed 173,122 people, of which $65 \%$ are men and $35 \%$ women.

Screen printing is a branch of graphic arts that consists of the technique of reproducing ideas through the pass of ink through a mesh prepared to deposit it on a surface.

Within the graphic arts industry, there is a manufacturer of screen printing equipment and machinery located on the northwest of Mexico Valley. It was founded in 1976, and now 
it lives its second management generation. It has as a leader product in sales, a printer machine, although its operation covers the sale of supplies related to this printing way. It has a familiar structure, with a traditional technology in its process of manufacture production. This MSME, named $\mathrm{SAB}$, will be the study case.

\section{METHODOLOGY}

\section{A. General procedure}

This work is made with a general procedure with an exploratory scope, since there is no relevant information in the literature on the decomposition of the productivity index into its main factors, labor and capital, which are important to expand its usefulness to serve as a guide to MSME. First, company information is collected, using official sources, in this case, sales data and costs reported in tax payments. Next, a descriptive statistical analysis is performed with this information, applied in the proposed formula and then, an inferential analysis of the significance with respect to a classical mathematical equation, which is that of Sumanth.

\section{B. Statement of the Hypothesis.}

The hypothesis to be tested is stated as follows: The productivity index of the MSME of graphic arts can be expressed in terms of the reason for the Cobb - Douglas production function and the values of the resources used.

\section{DISCUSSION}

\section{A. Collect information and analysis}

$\mathrm{SAB}$ reported the information with respect to the last fiscal year, which is shown in Table I; the values are in Mexican money. Into a first analysis and applying the mathematical expression of Sumanth productivity, it is obtains a result of 0.5955 . This means that, for every peso invested, the MSME only gets 59 cents as a return. Here, it cannot be determined whether it is good or bad, because it does not offer more information. If it is wants to compare with another company, however similar they may be, the comparison criteria would not be fair. However, more information can be obtained if the production volume is separating in their main factors with the Cobb-Douglas production function.

TABLE I

SPECIFIC VALUES FOR THE MSME, ACCORDING TO ITS LAST YEAR

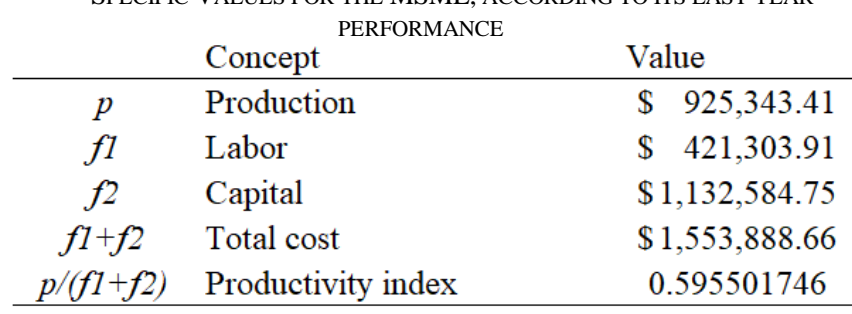

In the last year, the MSME obtained incomes for equivalent to 25 printer machines, each one with a unit cost of $\$ 37,013.74$; with the information of Table 1, investment of $\$ 1,132,584.75$ in Capital, 4, 200 Labor hours, at a cost per hour of $\$ 100.31$, equal to $\$ 421,303.91$, and the value for productivity constant $\mathrm{A}=0.5955$, the elasticity constant $(\alpha)$ can obtain with a simple math operation, and it is equal to 0.5887 . These values are harnessed to determine the production index $\boldsymbol{i}_{\boldsymbol{p}}$, using the Cobb - Douglas production function, summarized in Table II.

TABLE II

SPECIFIC VALUES USED IN THE DETERMINATION OF THE PRODUCTIVITY INDEX ip WITH THE COBB - DOUGLAS FUNTION

\begin{tabular}{|c|c|c|}
\hline Concept & Symbol & Quantity \\
\hline Labor (hours per year) & $\mathrm{x}$ & 4200 \\
\hline Capital & $\mathrm{y}$ & $\$ 1,132,584.75$ \\
\hline Productivity constant & A & 0.5955 \\
\hline Elasticity constant & $\alpha$ & 0.5887 \\
\hline Cost per hour of Labor & c & 100.31 \\
\hline
\end{tabular}

With these data, the Cobb - Douglas function to MSME is defined by Equation 4, and its productivity index by Equation 5 .

$$
\begin{aligned}
& p=0.5955 x^{0.5887} y^{(1-0.5887)} \\
& i_{p}=\frac{0.5955 x^{0.5877} y^{0.4123}}{0.1 x+y}
\end{aligned}
$$

The behavior of Equation 4 is ascending parabolically, with a slight tendency to grow more in the Labor factor, since its elasticity constant is slightly higher than that of Capital, as shown in Figure 1. In this graphic, Capital and Labor are on horizontal plane, and $f(x, y)=p$ is on the vertical line.

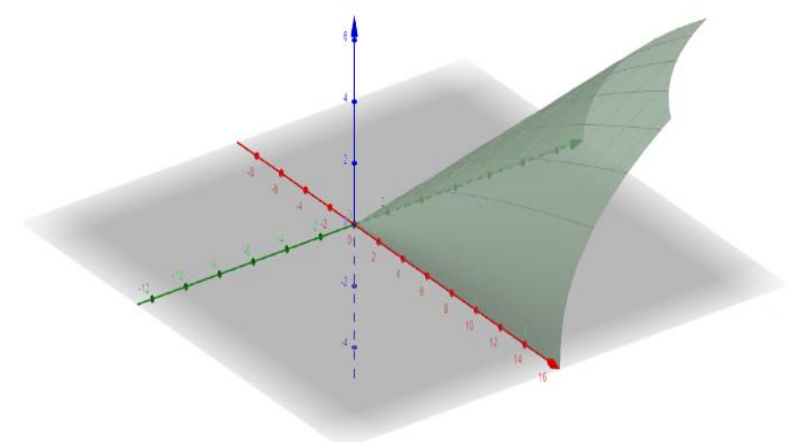

Fig. 1. 3D graph of the behavior of the Cobb - Douglas function for the MSME (own elaboration).

But, when Equation 5 is plotted with the variables of Capital and Labor, then a behavior is observed that is better at lower values, as shown in Figure 2. Due Labor has a greater impact on the productivity index, since this is indicated by its elasticity constant, it is convenient to initiate improvement actions for this factor.

With this analysis, it can be seen that as the amount of Labor and Capital increases, the volume of production 
increases with a range up to infinity, only limited by the restrictions of the resources available to the MSME. However, the productivity index prevents the inappropriate use of resources, so it is necessary to consider each increment in terms of its impact on said productivity index.

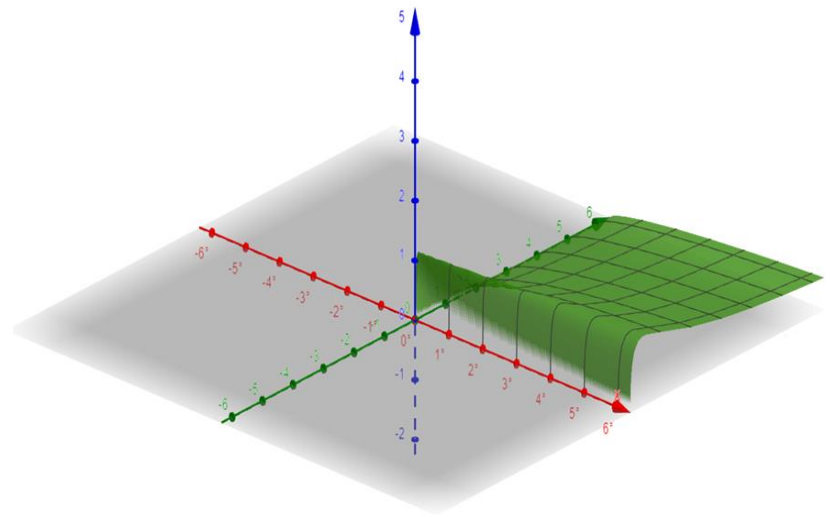

Fig. 2. 3D graph of the behavior of the productivity index using Cobb Douglas function for the MSME (own elaboration)

\section{B. Model Validation}

The model validation is through Equation 5, where $x$ is expressed in hundreds of hours per year, $y$ in thousands of Mexican pesos, $\mathrm{A}=0.5955, \alpha=0.5887$, and $c=0.1$ thousand Mexican pesos per hour. Eight capital values are established, from $\$ 1,000$ thousand Mexican pesos, to $\$ 1,700$, with increases of $\$ 100$. In the same way, 3.7 hundreds of hours per year are considered up to 7.2, with increments of 0.5 until to have 8 strata of study; a combination of 64 values is generated for the different amounts of Capital and Labor. These results are shown in Table III.

\section{TABLE III}

MATRIX OF THE PRODUCTIVITY INDICES CALCULATED FOR DIFFERENT VALUES OF AMOUNT OF WORK AND CAPITAL (OWN ELABORATION). Capital (Thousands of Mexican pesos)

\begin{tabular}{|c|c|c|c|c|c|c|c|c|c|}
\hline & & 1000 & 1100 & 1200 & 1300 & 1400 & 1500 & 1600 & 1700 \\
\hline \multirow{8}{*}{ 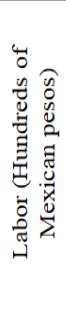 } & 3.7 & 0.594487 & 0.576178 & 0.559120 & 0.543218 & 0.528378 & 0.514506 & 0.501517 & 0.489330 \\
\hline & 4.2 & 0.618014 & 0.600419 & 0.583867 & 0.568312 & 0.553695 & 0.539952 & 0.527017 & 0.514826 \\
\hline & 4.7 & 0.637885 & 0.621114 & 0.605181 & 0.590085 & 0.575802 & 0.562294 & 0.549513 & 0.537415 \\
\hline & 5.2 & 0.654753 & 0.638877 & 0.623641 & 0.609085 & 0.595217 & 0.582022 & 0.569474 & 0.557542 \\
\hline & 5.7 & 0.669124 & 0.654186 & 0.639698 & 0.625738 & 0.612344 & 0.599523 & 0.587267 & 0.575559 \\
\hline & 6.2 & 0.681397 & 0.667419 & 0.653711 & 0.640387 & 0.627508 & 0.615105 & 0.603186 & 0.591748 \\
\hline & 6.7 & 0.691893 & 0.678881 & 0.665971 & 0.653307 & 0.640974 & 0.629021 & 0.617474 & 0.606341 \\
\hline & 7.2 & 0.700872 & 0.688822 & 0.676718 & 0.664728 & 0.652960 & 0.641481 & 0.630330 & 0.619528 \\
\hline
\end{tabular}

The form used to validate the model is through statistical analysis using hypothesis tests. A sample of $25 \%$ of the values is taken, it is mean, 16 of the 64 productivity indices in Table III. The cells are listed from 1 to 64 as shown in Table IV, forming 8 horizontal rows. Two numbers are extracted from each row using the "randbetween" Excel function; so, to validate the random numbers that are used in this work, the test procedure of the $\chi^{2}$, Chi square test, because the generator is expected to produce discretely distributed numbers evenly. The frequency observed and expected are located in two columns, getting of either their differences or errors and square error. The sum of these square errors is necessary for Chi-square test, as shown in Table V.

TABLE IV

NUMBERING OF THE MATRIX CELLS FOR THE RANDOM SAMPLE INSACULATION PROCESS (OWN ELABORATION) Capital (Thousands of Mexican pesos)

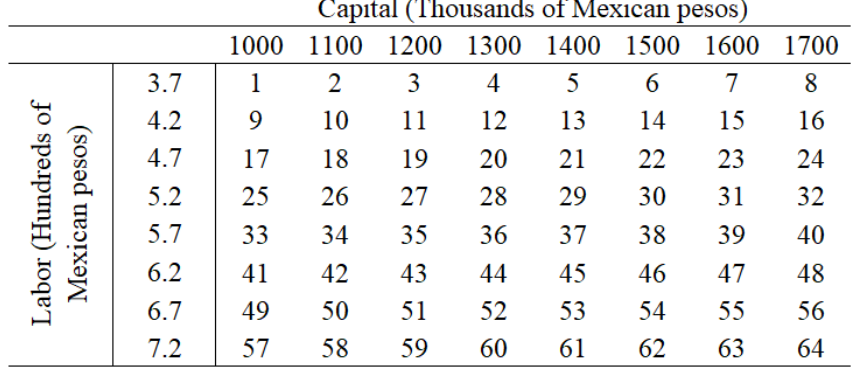

TABLE V

FREQUENCY VALUES EXPECTED AND OBSERVED, AS WELL AS ERRORS FOR THE TEST OF $\chi^{2}$ (OWN ELABORATION).

\begin{tabular}{cccccc}
\hline \multirow{2}{*}{ Labor } & \multicolumn{2}{c}{ Frecuency } & Error & Error $^{2}$ & $\frac{\text { Error }^{2}}{E_{i}}$ \\
\cline { 2 - 3 } & Expected (Ei) & Observed (Oi) & & & 0 \\
\hline $\mathbf{3 7 0}$ & $\mathbf{2}$ & $\mathbf{2}$ & 0 & 0 & 0 \\
$\mathbf{4 2 0}$ & $\mathbf{2}$ & $\mathbf{4}$ & 2 & 4 & 2 \\
$\mathbf{4 7 0}$ & $\mathbf{2}$ & $\mathbf{2}$ & 0 & 0 & 0 \\
$\mathbf{5 2 0}$ & $\mathbf{2}$ & $\mathbf{2}$ & 0 & 0 & 0 \\
$\mathbf{5 7 0}$ & $\mathbf{2}$ & $\mathbf{1}$ & -1 & 1 & 0.5 \\
$\mathbf{6 2 0}$ & $\mathbf{2}$ & $\mathbf{1}$ & -1 & 1 & 0.5 \\
$\mathbf{6 7 0}$ & $\mathbf{2}$ & $\mathbf{2}$ & 0 & 0 & 0 \\
$\mathbf{7 2 0}$ & $\mathbf{2}$ & $\mathbf{2}$ & 0 & 0 & 0 \\
\hline $\boldsymbol{2}$ & & & & & $\mathbf{3}$ \\
\hline
\end{tabular}

If the numbers come from a random number generator that works properly, a uniform discrete distribution must be manifested, which implies that each of the integers generated between 1 and 64 must be presented 8 times. Using a 95\% confidence level, that is $\alpha=5 \%$, the null hypothesis is established as the form of the random number distribution is the uniform discrete it is not possible to reject it, since Figure 3 shows the eight-step hypothesis-testing procedure for random numbers in the validation process, as Montgomery proposes [36]. 
1. The variable of interest is the form of the distribution of random numbers in the range 1 to 64 .
2. $H_{0}$ : The form of the distribution of random numbers is discret uniform.
3. $H_{1}$ : The form of the distribution of random numbers is not discret uniform.
4. $\alpha=0.05$
5. The test statistic is $\chi_{0}^{2}=\sum_{i=1}^{k} \frac{\left(o_{i}-E_{i}\right)^{2}}{E_{i}}$
6. Reject $H_{0}$ if $\chi_{0}^{2}>\chi_{0.05,3}^{2}=7.81$.
7. Computations: $\chi_{0}^{2}=3$
8. Conclusions: Since $\chi_{0}^{2}=3<\chi_{0.05,3}^{2}=7.81$, we are unable to reject the null hypothesis.

Fig. 3 The eight-step hypothesis-testing procedure for random numbers in the validation process (own elaboration).

The selected numbers are in Table VI together with their Labor, Capital and values.

Once the randomness is confirmed, Table IV is made with the values of the proposal $i_{p}$ calculated with Equation 2, agreeing the results of the productivity index as determined by Sumanth mathematical expression, that is, production obtained among the resources used to obtain it. The values of the mean, standard deviation and variance for each sample have also been calculated, with which the test of differences of means for two populations is applied. It is based on the assumption that both samples should not have a significant variation when a $95 \%$ confidence level is used.

TABLE VI

FREQUENCY VALUES EXPECTED AND OBSERVED, AS WELL AS ERRORS FOR THE TEST (OWN ELABORATION).

\begin{tabular}{|c|c|c|c|c|c|c|}
\hline Sample & Rand\# & Labor & Capital & Units & $i p$ & Ip Sumanth \\
\hline 1 & 2 & 370 & 1100 & 23 & 0.576178146 & 0.579126488 \\
\hline 2 & 3 & 370 & 1200 & 24 & 0.559119631 & 0.565815079 \\
\hline 3 & 9 & 420 & 1000 & 24 & 0.618014255 & 0.619118519 \\
\hline 4 & 11 & 420 & 1200 & 26 & 0.583866546 & 0.584944584 \\
\hline 5 & 15 & 420 & 1600 & 29 & 0.527016656 & 0.528039277 \\
\hline 6 & 16 & 420 & 1700 & 30 & 0.51482600 & 0.515835167 \\
\hline 7 & 19 & 470 & 1200 & 27 & 0.605180609 & 0.598425678 \\
\hline 8 & 23 & 470 & 1600 & 31 & 0.549513332 & 0.554311994 \\
\hline 9 & 27 & 520 & 1200 & 29 & 0.62364050 & 0.624748453 \\
\hline 10 & 29 & 520 & 1400 & 31 & 0.595216836 & 0.596304272 \\
\hline 11 & 37 & 570 & 1400 & 33 & 0.61234390 & 0.613444257 \\
\hline 12 & 48 & 620 & 1700 & 37 & 0.591748136 & 0.592832766 \\
\hline 13 & 51 & 670 & 1200 & 34 & 0.665971491 & 0.667099488 \\
\hline 14 & 53 & 670 & 1400 & 36 & 0.640974236 & 0.642092181 \\
\hline 15 & 59 & 720 & 1200 & 35 & 0.676717609 & 0.677847893 \\
\hline 16 & 63 & 720 & 1600 & 40 & 0.63032978 & 0.638167869 \\
\hline \multicolumn{5}{|c|}{ Means $=$} & 0.598166104 & 0.599884623 \\
\hline \multicolumn{5}{|c|}{ Standard deviations $=$} & 0.045873324 & 0.045605303 \\
\hline & & \multicolumn{3}{|c|}{ Variances $=$} & 0.002104362 & 0.002079844 \\
\hline
\end{tabular}

To prove that there is no significant difference, a hypothesis test is performed, following the procedure that Montgomery establishes [36]. So, using data of Table VI, with two samples, proposal equation, and Sumanth mathematical expression, production divided by resources, it is possible to get values for productivity index for both ways. Then, the sample 1 has the index productivity by the proposal, and the sample 2 is with the Sumanth expression.

In every sample, are calculated the means and variances, considering every sample independent. Now, to test their significance, the hypothesis test of difference of means is considered, in which both samples are considered to be equal, and therefore, their difference is zero. The null hypothesis is defined bay this condition, the difference between two samples mean is zero.

Using $\alpha=0.05$ as level of significance, the test statistic is $t_{o}$, since it is not certain that both samples have normal behavior. Too, it seems reasonable to combine the two sample variances with a pooled estimator, $S_{p}$. The procedure is shown in the Figure 4, using the eight-step hypothesis-testing procedure for a Difference in Means of productivity indexes, by Montgomery.

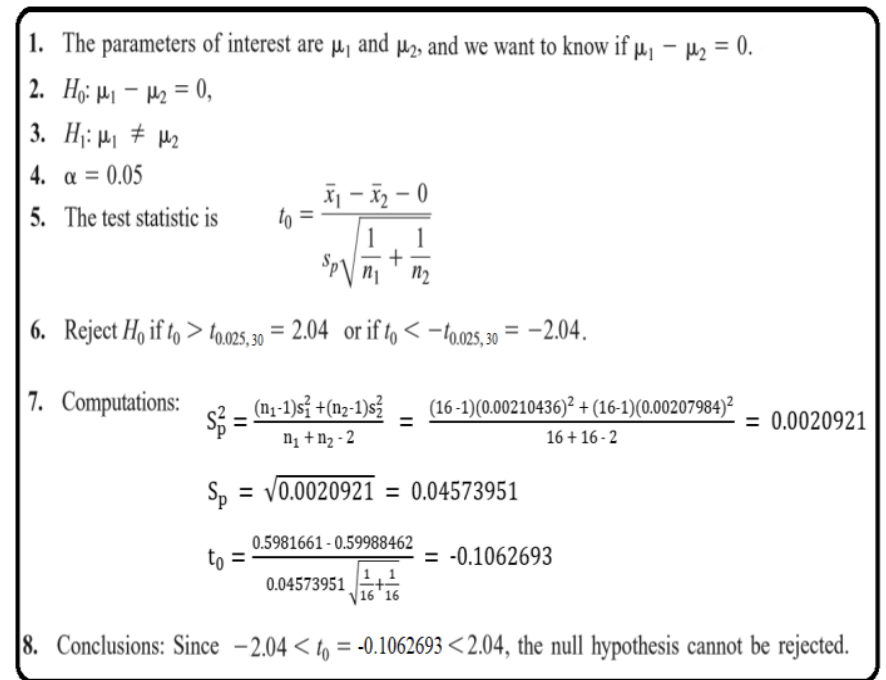

Fig. 4. The eight-step hypothesis-testing procedure for a Difference in Means of productivity indexes (own elaboration).

Due, the null hypothesis cannot be rejected, It is verified that the Equation proposed in (2), is valid and can be used to calculate and productivity index.

\section{CONCLUSIONS}

Through this work, it has been found that it is possible to express the productivity index in terms of the Cobb - Douglas production function. The advantage of using this expression in this index is due to finding the factors that affect it, such as labor and capital, to determine the values that guide MSMEs to improve this systemic indicator.

Since an analysis of descriptive and inferential statistics, you can specify the way in which work and capital are behaving at this time, and decide on strategies that directly impact a better result in the productivity index. When 
comparing this proposed equation with the classic model, it is concluded that there is no significant difference, so it can be used in the company.

\section{ACKNOWLEDGMENT}

Special thanks are made to the SAB enterprise, especially $\mathrm{Mr}$. Ramón Bernal $(\dagger)$ for his valuable support in allowing his company's information to be considered. Likewise, to CONACYT for the support granted in the realization of this work, and to ESIME of the IPN, headquarters of the Doctorate in Systems Engineering. Special thanks to TESCI for the facilities granted.

\section{REFERENCES}

[1] C. Andersson and M. Bellgran. "On the complexity of using performance measures: Enhancing sustained production improvement capability by combining OEE and productivity". Journal of Manufacturing Systems. Vol. 35, pp. $144-154,2015$.

[2] M. Bellgran and K. Säfsten. "Production development: design and operation of production systems. London: Springer Verlag, 2010.

[3] A. P. Cusolito and W. Maloney. Productivity Revisited Shifting Paradigms in Analysis and Policy. International Bank for Reconstruction and Development / The World Bank, 2018.

[4] M. Martínez. The concept of productivity in economic analysis. Aportes. Vol. 3, 7, 1998, pp $95-118$.

[5] D. Sumanth, and M. Dedeoglu. Application of expert systems to productivity measurement in companies/organizations. Computers industrial engineers. Vol. 13, No 1-4, 1987, pp.21-25.

[6] D. Sumanth. Total Productivity Management. A systemic and quantitative approach to compete in quality, price and time. USA: St. Lucie Press. $1998 .$.

[7] P. Sraffa. The works and correspondence of David Ricardo Vol 1. On the principles of Political economy and Taxation. London: Cambridge University Press. 1950.

[8] Marx, C. El Capital, Siglo XXI editores, México, España, Argentina, Tomo I/Vol.2, Cap. XV. 1980.

[9] M. Anteby, and R. Khurana. A new vision. Baker Library. Historical Collections. Harvard Business Review. (s/f).

[10]W. French and C. Bell. Organizational development: Interventions of behavioral science for the improvement of the organization. USA: Pearson. 2007.

[11]E. Hernández Laos, Evolución de la productividad total de los factores en la economía mexicana 1970-1989, México: STPS. 1993.

[12]E. Goldratt and J. Cox. The goal: A Process of Ongoing Improvement. USA: The North River Press, P. C. 1984

[13]R. Kaplan and R. Cooper. Cost and effect: using integrated systems to drive profitability and performance. Boston: Harvard Business School Press. 1998.

[14]I. Bernolak. Effective measurement and successful elements of company productivity: the basis of competitiveness and world prosperity. Int J Prod Econ; Vol. 52, 1 - 2, 1997, pp203 - 213.

[15]T. Grünberg. Performance improvement: a method to support performance improvement in industrial operations. Sweden: Dept of production Engineering, Royal Institute of Technology. 2007.

[16]P. White. A survey and taxonomy of strategy - related performance measures for manufacturing. Int J Operation Production Management, vol 16, 3, 1996, pp $42-61$.

[17]H. Huang, J. Dismukes, J. Shi, and E Robinson. Manufacturing system modeling for productivity improvement. Journal manufacturing Systems, Vol. 21, 4, 2002, pp. $249-259$.

[18]G. Chakravarthy, P. Keller, B. Wheeler and S. Van Oss. A methodology for measuring reporting, navigating and analyzing overall equipment efficiency (OEE). Proceedings from IEEE/SEMI advanced semiconductor manufacturing conference. 2007, pp $3026-3012$.
[19]C. Hulten. Total Factor Productivity: A Short Biography. New Developments in Productivity Analysis, Chicago, University of Chicago Press, 1-47. 2001.

[20]M. Nishimizu and J. Page. Total Factor Productivity Growth, Technological Progress and Technical Efficiency Change: Dimensions of Productivity Change in Yugoslavia, 1965-1978, Economic Journal, Vol. 92, 368, 1982, pp. 920-936.

[21]D. Caves, L. Christensen and W. Diewert (1982). The Economic Theory of Index Numbers and the Measurement of Inputs, Outputs and Productivity, Econometrica. Vol. 50, 6, 1982, pp 1393 - 1414.

[22]K. Kerstens, Z, Shen and I: Van de Woestyne. Comparing Luenberger and Luenberger-Hicks-Moorsteen Productivity Indicators: How Well is Total Factor Productivity Approximated? International Journal of Production Economics. Vol. 195, pp. 311 - 318, January 2018.

[23]R. Färe, S. Grosskopf, M. Norris, and Z. Zhang. Productivity Growth, Technical Progress, and Efficiency Change in Industrialized Countries, American Economic Review. Vol 84, 1, 1994, pp. 66 - 83.

[24]S. Atkinson, C. Cornwell, O. Honerkamp. Measuring and Decomposing Productivity Change: Stochastic Distance Function Estimation Versus Data Envelopment Analysis. Journal of Business and Economic Statistics. Vol. 21, 2. 2003, pp. $284-294$

[25]H. Bjurek. The Malmquist Total Factor Productivity Index. Scandinavian Journal of Economics. Vol. 98, 2. 1996, pp. 303 - 313.

[26]R. Färe, S. Grosskopf and P. Roos. On Two Definitions of Productivity, Economics Letters. Vol. 53, 3. 1996, pp. 269 - 274.

[27]R. Chambers, R. Färe and S. Grosskopf. Input and Output Indicators. Index Numbers: Essays in Honour of Sten Malmquist. Boston, Kluwer, pp. 241271. 1998.

[28]R.Chambers, Exact Nonradial Input, Output, and Productivity Measurement, Economic Theory. Vol. 20, 4. 2002, pp. $751-765$.

[29]W. Briec, K. Kerstens, and P. Vanden Eeckaut. Non-convex Technologies and Cost Functions: Definitions, Duality and Nonparametric Tests of Convexity. Journal of Economics. Vol. 81, 2. 2004, pp. 155-192.

[30]C. Cobb and P. Douglas. A theory of Production. The American Economic Review, Vol. 18, No. 1, Supplement, Papers and Proceedings of the Fortieth Annual Meeting of the American Economic. 1928, pp. 139 - 165.

[31]R. Solow. Technical Change and the Aggregate Production Function. The Review of Economics and Statistics. Vol. 39, No. 3. 1957, pp. 312320.

[32]H. Arrow, B. Chenery, B. Minhas, and R. Solow. Capital -Labor Substitution and Economic Efficiency. The Review of Economics and Statistics, Vol. 43, No. 3, 1961, pp. 225 - 250.

[33]X. Wang and Y. Fu. Some Characterizations of the Cobb-Douglas and CES Production Functions in Microeconomics. Hindawi Publishing Corporation. Abstract and Applied Analysis Vol. 2013, Article ID 761832, 6 pages, 2013.

[34]J. Cadil, K. Vltsaka, I. Krejci, D. Hartman and M. Brabec. Aggregate production function and income identity- empirical analysis. International Journal of Economic Sciences. Vol. VI, No. 1, 2017.

[35]INEGI. Encuesta nacional sobre productividad y competitividad de las Micro, Pequeñas y Medianas Empresas. 2016.

[36]D. Montgomery and G. Runger. Applied statistics and probability for engineers. USA: John Wiley \& Sons. 